\title{
Use of the Chebyshev Polynomial Approximation in the Analysis of Milk Production and Average Weight at Birth Calves Depending on the Volume Food and the concentrate
}

\author{
Majlinda Belegu \\ Department of Mathematics and Informatics, Agricultural University of Tirana \\ Email: majlindabelegu @yahoo.com \\ Parashqevi Rrapo \\ Department of Mathematics and Informatics, Agricultural University of Tirana \\ Mariana Nikolla \\ Department of Mathematics and Informatics, Agricultural University of Tirana
}

Edmond Kadiu

Department of Rural Tourism Management, Agricultural University of Tirana

Irma Qinami

Department of Economics and Agricultural Policy, Agricultural University of Tirana

Xhevahire Dulja

Department of Rural Tourism Management, Agricultural University of Tirana

\section{Doi:10.5901/mjss.2013.v4n9p660}

\begin{abstract}
In this study published the influence of two nutritional factors of milk production and the use of the production functions in the farming sector. The production, profit, and management are key elements for efficient economy. The main purpose of the project is to use contemporary methods for economic analyses of the use of resources (inputs), more specifically in small family farms. Nowadays in order to have a sustainable development of the agricultural farms, especially the livestock farms, it requires an economic optimization, as well as continuous analyses of economic and technical of influential factors. The main method used on the above mentioned study is the ones of Cobb-Douglas production function. This method analyses the impact of nutritional factors (the structure of the nutritive ration; wet, dead, concentrate) on bovine milk production. As illustrated in the article the economic theory combined with the deep mathematic logic are two main directions for the treatment of production functions. The study was conducted in "Agrotex" farm in Lushnje district. They were processed and analyzed data on the feeding phase and data on milk yield and weight of calves at birth for a period of 5 years. They were processed and analyzed data feeding phases mentioned above and milk yield and weight of calves at birth. These data were analyzed for a period of 5 years (period 2008-2012) with a number of heads of: 103, 111, 176, 118, 139 respectively in 2008, 2009, 20010, 20011, 2012.During the study is used Cobb-Douglas production function to analyze the impact of two components ration on milk production and approaches in the Chebishev's polynomials to solve systems of constraints. It appears that the most appropriate structure of the ration, to provide an average yield of $6478.3 \mathrm{~kg}$ milk / lactation (305 days), or an average of $21.3 \mathrm{~kg}$ milk / day, should be as follows: $17558.7 \mathrm{~kg}$ voluminous food and $=2265.7 \mathrm{~kg}$ concentrate. We prove that maximum profit and minimum cost to achieve food $=17558.7 \mathrm{~kg}=2265.7 \mathrm{~kg}$ voluminous and concentrated. In this case the amount of milk produced by a cow will be $6478.3 \mathrm{~kg}$ while the average weight of calves at birth will be $43.8 \mathrm{~kg}$. This study confirms that balanced nutrition is the primary factor in increasing economic efficiency of farms. As a result, the study demonstrates that the maximum profits, as well as the maximum income, are reached at the same point in the expansion path, where the cost is minimal.
\end{abstract}

Keywords: optimal structure, milk production, nutritive factors, approaches in the Chebyshev's , optimal production, food ration 


\section{Introduction}

Milk production mainly from cattle is different in different areas of the country. Production in lowland areas has been increased as a result of the increased number of heads of cattle, their production and improving of the food base.

The phased nutrition is a program which means the feeding of the flock in the time period based on the level of the milk production, the milk fat content, the amount of the consumed food and the live weight of the animal. Producers I farmers should develop the rations so that they can meet the needs of the animals in each of these stages for an optimum output, to minimize or to avoid metabolic disorders, to increase the length of the animal life and increase profit by batches.

\section{Material And Method}

The study was conducted in "Agrotex" farm in Lushnje district. They were processed and analyzed data on the feeding phase and data on milk yield and weight of calves at birth for a period of 5 years. They were processed and analyzed data feeding phases (1. Up to 150 days lactation, 2. Above 150 day lactation, 3 . the drying period) the milk yield and weight of calves at birth. These data were analyzed for a period of 5 years (period 2008-2012) with a number of heads of: $103,111,176,118,139$ respectively in $2008,2009,20010,20011,2012$. During the study is used Cobb-Douglas production function to analyze the impact of two components ration on milk production and approaches in the Chebishev's polynomials to solve systems of constraints.

\section{Results And Discussion}

- Were defined the forms of the functions of the milk production and the average weight of calves at birth.

- It was confirmed the suitability of the chosen models.

- We found the optimum combination of the inputs (ration structure) to maximize the profit and to minimize the cost.

- Were grouped, analyzed and processed the average values of the milk production, the average quantities of food during a twelve month period, according to three phases of handling a cow: (1. Up to 150 days lactation, 2. Above 150 day lactation, 3 . the drying period) and the average weight of calves at birth in the twelfth month for those cows that were born in the twelfth month.

In table 1 are the voluminous amount of food, the concentration, the average milk production and the average weight of calves at birth.

Table 1: The milk production and the average weight of calves at birth

\begin{tabular}{|c|c|c|c|c|}
\hline $\mathrm{Nr}$ & $\begin{array}{c}\text { The voluminous } \\
\text { food }\end{array}$ & $\begin{array}{c}\text { The } \\
\text { concentration }\end{array}$ & $\begin{array}{c}\text { The milk } \\
\text { production }\end{array}$ & $\begin{array}{c}\text { The average weight } \\
\text { of calves at birth }\end{array}$ \\
\hline 1 & 11715 & 3771 & 6051.3 & 42.8 \\
\hline 2 & 11775.3 & 3832.2 & 6215.1 & 43.3 \\
\hline 3 & 11743.8 & 3801.6 & 6083.7 & 43.4 \\
\hline 4 & 11974.2 & 3862.8 & 6083.7 & 43 \\
\hline 5 & 11801.4 & 3801.6 & 6051.3 & 43.2 \\
\hline 6 & 12147.9 & 4138.2 & 6215.1 & 44 \\
\hline 7 & 12147.9 & 4015.8 & 6182.7 & 43.5 \\
\hline 8 & 12175.8 & 4077 & 6248.4 & 43.5 \\
\hline 9 & 12233.4 & 4015.8 & 6182.7 & 43 \\
\hline 10 & 12378.3 & 4138.2 & 6248.4 & 44.5 \\
\hline 11 & 12493.5 & 4260.6 & 6314.1 & 43.9 \\
\hline 12 & 12291.9 & 4046.4 & 6280.8 & 44.3 \\
\hline 13 & 12378.3 & 4260.6 & 6378.9 & 44.6 \\
\hline 14 & 12493.5 & 4352.4 & 6412.2 & 43.8 \\
\hline 15 & 12319.8 & 4107.6 & 6280.8 & 45 \\
\hline 16 & 12407.1 & 4168.8 & 6346.5 & 44.8 \\
\hline 17 & 12405.3 & 4230 & 6378.9 & \\
\hline
\end{tabular}




\begin{tabular}{|c|c|c|c|c|}
\hline 18 & 12378.3 & 4168.8 & 6346.5 & 44.2 \\
\hline 19 & 11265.6 & 3465.2 & 5882.6 & 41.9 \\
\hline 20 & 11139.9 & 3433.5 & 5788.5 & 41.2 \\
\hline 21 & 10908.6 & 3341.7 & 5755.2 & 41 \\
\hline 22 & 10474.8 & 3096.9 & 5525.7 & 39.2 \\
\hline 23 & 10793.4 & 3249.9 & 5722.8 & 40.7 \\
\hline 24 & 11369.4 & 3555.9 & 5985.6 & 42.6 \\
\hline 25 & 10618.8 & 3158.1 & 5591.4 & 39.7 \\
\hline 26 & 11571 & 3893.4 & 6018 & 42.8 \\
\hline 27 & 10907.7 & 3341.7 & 5722.8 & 40.6 \\
\hline 28 & 10822.2 & 3280.5 & 5722.8 & 40.5 \\
\hline 29 & 10793.4 & 3188.7 & 5689.5 & 40.3 \\
\hline 30 & 11341.5 & 3771 & 5952.3 & 42.3 \\
\hline 31 & 11022.9 & 3402.9 & 5755.2 & 40.9 \\
\hline 32 & 11081.4 & 3402.9 & 5788.5 & 40.6 \\
\hline 33 & 10995 & 3372.3 & 5755.2 & 41 \\
\hline 34 & 11399.1 & 3587.4 & 5919.9 & 42 \\
\hline 35 & 11023.8 & 3341.7 & 5788.5 & 40.8 \\
\hline 36 & 11542.2 & 3679.2 & 5985.6 & 42.1 \\
\hline 37 & 10590 & 3158.1 & 5558.1 & 39.3 \\
\hline 38 & 11429.7 & 3618 & 5952.3 & 42.4 \\
\hline 39 & 10677.3 & 3219.3 & 5591.4 & 39.7 \\
\hline 40 & 11513.4 & 3771 & 6051.3 & 43.2 \\
\hline 41 & 12579.9 & 4260.6 & 6346.5 & 45.4 \\
\hline 42 & 12666.3 & 4321.8 & 6378.9 & 45.2 \\
\hline 43 & 12608.7 & 4291.2 & 6378.9 & 45.5 \\
\hline 44 & 12724.8 & 4352.4 & 6510.3 & 46.1 \\
\hline 45 & 12752.7 & 4383 & 6444.6 & 45.6 \\
\hline 46 & 12696 & 4383 & 6412.2 & 45.7 \\
\hline 47 & 12811.2 & 4413.6 & 6510.3 & 46.6 \\
\hline 48 & 11601.6 & 3801.6 & 6083.7 & 43.3 \\
\hline
\end{tabular}

The average prices for $1 \mathrm{~kg}$ of wet food, for $1 \mathrm{~kg}$ of dry food and for $1 \mathrm{~kg}$ of concentrate are $3.8 \mathrm{~L}, 4.8 \mathrm{~L}$ and $15.2 \mathrm{~L}$ Production function was made in the form $y=A x_{1}^{\alpha} x_{2}{ }^{\beta} x_{3}^{\gamma}$

It was used the linear regression method to determine $\log A, \alpha, \beta$ dhe $\gamma$, through the econometric and computeric software package SPSS. Resulted that the models are suitable. Given from these data were built the two production functions given below:

$$
\begin{aligned}
& y_{1}=23.31274017 \cdot x_{1}^{0.424} \cdot x_{2}^{0.192} \\
& y_{2}=0.3201390009 \cdot x_{1}^{0.331} \cdot x_{2}^{0.218}
\end{aligned}
$$

where $x_{1}, x_{2}, y_{1}$ and $y_{2}$ are marked respectively the amount of voluminous feed, of the concentrate, the average milk production and the average weight of calves at birth. Was verified the hypothesis on the importance of the regression, and it was shown that at least one of the variables gives the information for the prognosis of the $y$, that is to say that the model is useful for predicting the value of $\mathrm{y}$. Also, is confirmed the hypothesis of the importance of the parameters of the model.

\section{Minimize of the cost}

We have the functions: $y_{1}=A x_{1}^{\alpha} x_{2}^{\beta}, y_{2}=B x_{1}^{a} x_{2}^{b}$

Notice: $y_{1}=f\left(x_{1}, x_{2}\right), y_{2}=g\left(x_{1}, x_{2}\right)$

Remark with $r_{1}$ and $r_{2}$ respectively the prices of the inputs $x_{1}$ and $x_{2}$, and with $p_{1}$ and $p_{2}$ respectively the prices of the outputs. 
We formed the Lagrange $\mathrm{LC}$ to have the minimum of the cost:

$$
L C=r_{1} x_{1}+r_{2} x_{2}+\lambda_{1}\left[y_{1}-f\left(x_{1}, x_{2}\right)\right]+\lambda_{2}\left[y_{2}-g\left(x_{1}, x_{2}\right)\right]
$$

and we expressed the necessary conditions for the minimum of the LC:

$$
\begin{aligned}
& \frac{\partial L C}{\partial x_{1}}=r_{1}-\lambda_{1} f_{x_{1}}^{\prime}\left(x_{1}, x_{2}\right)-\lambda_{2} g_{x_{1}}^{\prime}\left(x_{1}, x_{2}\right)=0 \\
& \frac{\partial L C}{\partial x_{2}}=r_{2}-\lambda_{1} f_{x_{2}}^{\prime}\left(x_{1}, x_{2}\right)-\lambda_{2} g_{x_{2}}^{\prime}\left(x_{1}, x_{2}\right)=0 \\
& \frac{\partial L C}{\partial \lambda_{1}}=y_{1}-f\left(x_{1}, x_{2}\right)=0 \\
& \frac{\partial L C}{\partial \lambda_{2}}=y_{2}-g\left(x_{1}, x_{2}\right)=0
\end{aligned}
$$

From the last two equations we expressed $x_{1}$ and $x_{2}$ depending on $y_{1}$ and $y_{2}$.

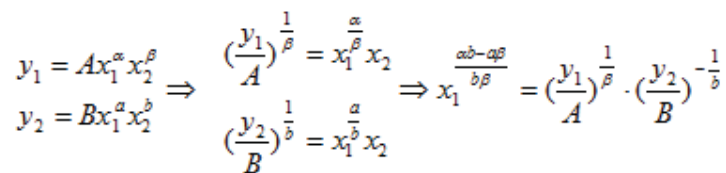

Are considered the sufficient conditions for the minimum of the LC with side of the determinant of the border Hessian and we have proved that the cost function has the minimum in the values $x_{1}$ and $x_{2}$ expressed in equations $(*)$

$$
\begin{aligned}
& x_{1}=\left(\frac{y_{1}}{A}\right)^{\frac{b}{\alpha b-\beta a}} \cdot\left(\frac{y_{2}}{B}\right)^{-\frac{\beta}{\alpha b-\beta a}} \\
& x_{2}=\left(\frac{y_{1}}{A}\right)^{-\frac{a}{\alpha b-\beta a}} \cdot\left(\frac{y_{2}}{B}\right)^{\frac{\alpha}{\alpha b-\beta a}} \\
& \lambda_{1}=\frac{1}{y_{1}(\alpha b-\beta a)}\left[b r_{1}\left(\frac{y_{1}}{A}\right)^{\frac{b}{\alpha b-\beta a}}\left(\frac{y_{2}}{B}\right)^{\frac{-\beta}{\alpha b-\beta a}}-a r_{2}\left(\frac{y_{1}}{A}\right)^{\frac{-a}{\alpha b-\beta a}}\left(\frac{y_{2}}{B}\right)^{\frac{\alpha}{\alpha b-\beta a}}\right] \\
& \lambda_{2}=-\frac{1}{y_{2}(\alpha b-\beta a)}\left[\beta r_{1}\left(\frac{y_{1}}{A}\right)^{\frac{b}{\alpha b-\beta a}}\left(\frac{y_{2}}{B}\right)^{\frac{-\beta}{\alpha b-\beta a}}-\alpha r_{2}\left(\frac{y_{1}}{A}\right)^{\frac{-a}{\alpha b-\beta a}}\left(\frac{y_{2}}{B}\right)^{\frac{\alpha}{\alpha b-\beta a}}\right] \\
& \overline{|H|}=\left|\begin{array}{cccc}
0 & 0 & \frac{\alpha y_{1}}{x_{1}} & \frac{\beta y_{1}}{x_{2}} \\
0 & 0 & \frac{a y_{2}}{x_{1}} & \frac{b y_{2}}{x_{2}} \\
\frac{\alpha y_{1}}{x_{1}} & \frac{a y_{2}}{x_{1}} & L_{x_{1} x_{1}}^{\prime \prime} & L_{x_{1} x_{2}}^{\prime \prime} \\
\frac{\beta y_{1}}{x_{2}} & \frac{b y_{2}}{x_{2}} & L_{x_{2} x_{1}}^{\prime \prime} & L_{x_{2} x_{2}}^{\prime \prime}
\end{array}\right|=\left(\frac{y_{1} y_{2}}{x_{1} x_{2}}\right)^{2}(\alpha b-a \beta)^{2}>0
\end{aligned}
$$




\section{The profit maximization}

We have examined the function of profit to maximize the profit:

$$
F=p_{1} f\left(x_{1}, x_{2}\right)+p_{2} g\left(x_{1}, x_{2}\right)-r_{1} x_{1}-r_{2} x_{2}
$$

Are considered necessary conditions for the maximum of the profit.

$$
\begin{aligned}
& \frac{\partial F}{\partial x_{1}}=p_{1} f_{x_{1}}^{\prime}\left(x_{1}, x_{2}\right)+p_{2} g_{x_{1}}^{\prime}\left(x_{1}, x_{2}\right)-r_{1}=0 \\
& \frac{\partial F}{\partial x_{2}}=p_{1} f_{x_{2}}^{\prime}\left(x_{1}, x_{2}\right)+p_{2} g_{x_{2}}^{\prime}\left(x_{1}, x_{2}\right)-r_{2}=0
\end{aligned}
$$

So we have to solve the system (**):

$$
\left\{\begin{array}{l}
p_{1} \alpha y_{1}+p_{2} a y_{2}=r_{1} x_{1} \\
p_{1} \beta y_{1}+p_{2} b y_{2}=r_{2} x_{2} \\
y_{1}=A x_{1}^{\alpha} x_{2}^{\beta} \\
y_{2}=B x_{1}^{a} x_{2}^{b}
\end{array}\right.
$$

We have seen if completed the sufficient conditions for the maximum of the profit before we solve the system ( $\left.{ }^{\star *}\right)$. For this we determined the sign of the determinant of Hessian and its main minors.

$$
\begin{aligned}
& \frac{\partial^{2} F}{\partial x_{1}^{2}}=\frac{\alpha(\alpha-1) p_{1} y_{1}}{x_{1}^{2}}+\frac{a(a-1) p_{2} y_{2}}{x_{1}^{2}} \\
& \frac{\partial^{2} F}{\partial x_{2}^{2}}=\frac{\beta(\beta-1) p_{1} y_{1}}{x_{2}^{2}}+\frac{b(b-1) p_{2} y_{2}}{x_{2}^{2}} \\
& \frac{\partial^{2} F}{\partial x_{1} \partial x_{2}}=\frac{\alpha \beta p_{1} y_{1}}{x_{1} x_{2}}+\frac{a b p_{2} y_{2}}{x_{1} x_{2}}=\frac{\partial^{2} F}{\partial x_{2} \partial x_{1}}
\end{aligned}
$$

Since $\alpha=0.424, \beta=0.192, a=0.331, b=0.218$ appears that $\frac{\partial^{2} F}{\partial x_{1}^{2}}<0$ and

$$
\left|H_{2}\right|=\left|\begin{array}{ll}
\frac{\partial^{2} F}{\partial x_{1}^{2}} & \frac{\partial^{2} F}{\partial x_{1} \partial x_{2}} \\
\frac{\partial^{2} F}{\partial x_{2} \partial x_{1}} & \frac{\partial^{2} F}{\partial x_{2}^{2}}
\end{array}\right|>0
$$

So, the maximum of the profit is achieved for values $x_{1}$ and $x_{2}$ that are solutions of the system $\left.\left.{ }^{* *}\right)^{\text {. To }}{ }^{* *}\right)$ can be computed the values $f\left(x_{1}, x_{2}\right)$ and $g\left(x_{1}, x_{2}\right)$.

Then we passed to the resolution of the system $(* *)$.

Technically it is difficult to gauge the exact solution of system (**) so we find its approximate solution to a satisfactory approximation by the Chebishev polynomials, which has made it possible to identify areas where moves $y_{1}$ and $y_{2}$. These areas have served as the options to find the exact solution of the system (**) through MAPLE program.

Now let's implement the polynomial approximation of Chebishev hand to draw relevant conclusions. Polynomials of Chebishev are $T_{n}(x)=\cos (n \cdot \arccos x)$. So for example $T_{0}(x)=1, T_{1}(x)=x, T_{2}(x)=2 \cdot x^{2}-1, T_{3}(x)=4 \cdot x^{3}-3 \cdot x$. In general for polynomial $T_{n}(x)$ through the recurrence formula we have: $T_{n}(x)=2 \cdot x \cdot T_{n-1}(x)-T_{n-2}(x)$. Indeed if the identity $\cos (n \theta)+\cos ((n-2) \theta)=2 \cos \theta \cos ((n-1) \theta)$ substitute $\theta=\arccos x$ we have the above equations. On the segment $[-1,1]$ there are the points $\xi_{1}, \xi_{2}, \ldots, \xi_{n}$, which are the zeros of the polynomial 
$T_{n}(x)$ ie $\xi_{i}=\cos \left(\frac{2 i-1}{2 n} \pi\right), i=1,2 \ldots n$. Let it be given function $f(x)$ defined on the segment $[a, b]$. Through of the transformation $x=a+\frac{1}{2}(b-a)(\xi+1)$ the faces $\xi_{1}, \xi_{2}, \ldots, \xi_{n}$, on $[-1,1]$ reflect to the points $x_{1}, x_{2}, \ldots x_{n}$, on $[\mathrm{a}, \mathrm{b}]$, where $x_{i}=a+\frac{1}{2}(b-a)\left(\xi_{i}+1\right)$ or $x_{i}=\frac{1}{2}(b+a)+\frac{1}{2}(b-a) \xi_{i}$ (because this transformation reflect $[-1,1]$ to $[a . b])$. If the function $f(x)$ has at any point of the segment $[\mathrm{a}, \mathrm{b}]$ continuous derivatives of the $\mathrm{n}$-th order and satisfying $\left|f^{(n)}(x)\right| \leq M_{n}$ then the polynomial $p_{n-1}(x)$ of degree $\mathrm{n}-1$ that interpolon points $\left(x_{1}, f\left(x_{1}\right)\right),\left(x_{2}, f\left(x_{2}\right)\right), \ldots\left(x_{n}, f\left(x_{n}\right)\right)$, satisfies the condition $\left|f(c)-p_{n-1}(c)\right| \leq \frac{M_{n}}{2^{(2 n-1)} n !}(b-a)^{n}$ where c is the point of $[a, b]$.

To solve the system $\left(^{* *}\right)$ by approximating $y_{1}$ and $y_{2}$ with the Chebishev polynomials $\sum_{i=0}^{n} c_{i} T_{i}(x)$ where the coefficients determined by the equations,

$$
c_{0}=\frac{1}{n+1} \sum_{k=0}^{n} f\left(x_{k}\right) T_{0}\left(x_{k}\right)=\frac{1}{n+1} \sum_{k=0}^{n} f\left(x_{k}\right)^{\prime} c_{i}=\frac{2}{n+1} \sum_{k=0}^{n} f\left(x_{k}\right) T_{i}\left(x_{k}\right) \text { ku i }=1,2 \ldots, \mathrm{n} .
$$

Starting from the outcome of the case: 3 inputs and 1 output as [a, b] to $x_{1}$ we take [15250.15350], while to $x_{2}$ we take [1650.1750]. In our case we will have to

$$
\begin{aligned}
& x_{10.424}=59.4714988 \mathrm{~T}_{0}(\mathrm{u})+0.08240510611 \mathrm{~T}_{1}(\mathrm{u})-0.00003877896659 \mathrm{~T}_{2}(\mathrm{u})+0.33287476210^{-7} \mathrm{~T}_{3}(\mathrm{u}) . \\
& x_{20.192}=4.170917675 \mathrm{~T}_{0}(\mathrm{v})+0.02355793012 \mathrm{~T}_{1}(\mathrm{v})-0.0001399909463 \mathrm{~T}_{2}(\mathrm{v})+0.124096738710^{-5} \mathrm{~T}_{3}(\mathrm{v}) . \\
& x_{10.331}=24.27351146 \mathrm{~T}_{0}(\mathrm{u})+0.02625669614 \mathrm{~T}_{1}(\mathrm{u})-0.00001435112187 \mathrm{~T}_{2}(\mathrm{u})+0.130457972210^{-7} \mathrm{~T}_{3}(\mathrm{u}) . \\
& x_{20.218}=5.060831165 \mathrm{~T}_{0}(\mathrm{v})+0.03245494687 \mathrm{~T}_{1}(\mathrm{v})-0.0001866545327 \mathrm{~T}_{2}(\mathrm{v})+0.163082719910^{-5} \mathrm{~T}_{3}(\mathrm{v}) . \\
& \text { Where } u=\frac{1}{50} x_{1}-306 \text { dhe } \quad v=\frac{1}{50} x_{2}-34, \text { and } T_{0}(u)=1, T_{0}(v)=1 \\
& T_{1}(u)=\frac{1}{50} x_{1}-306, T_{2}(u)=2\left(\frac{1}{50} x_{1}-306\right)^{2}-1, T_{3}(u)=4\left(\frac{1}{50} x_{1}-306\right)^{3}-\frac{3}{50} x_{1}+918 \text { dhe } \\
& T_{1}(v)=\frac{1}{50} x_{2}-34, T_{2}(v)=2\left(\frac{1}{50} x_{2}-34\right)^{2}-1, T_{3}(v)=4\left(\frac{1}{50} x_{2}-34\right)^{3}-\frac{3}{50} x_{2}+102 .
\end{aligned}
$$
have to

To replacing the approaches by the Chebishev polynomials in third and fourth equation of the system (**) we will $10.6 y_{1}+115.85 y_{2}=4.2 x_{1}$

$4.8 y_{1}+76.3 y_{2}=15.2 x_{2}$

$y_{1}=23.31274017\left(59.4714988 \mathrm{~T}_{0}(\mathrm{u})+0.08240510611 \mathrm{~T}_{1}(\mathrm{u})-0.00003877896659 \mathrm{~T}_{2}(\mathrm{u})+0.33287476210^{-7}\right.$ $\left.T_{3}(u)\right)\left(4.170917675 T_{0}(v)+0.02355793012 T_{1}(v)-0.0001399909463 T_{2}(v)+0.124096738710^{-5} T_{3}(v)\right)$

$y_{2}=0.3201390009\left(24.27351146 \mathrm{~T}_{0}(\mathrm{u})+0.02625669614 \mathrm{~T}_{1}(\mathrm{u})-0.00001435112187 \mathrm{~T}_{2}(\mathrm{u})+0.130457972210^{-7}\right.$ $\left.\mathrm{T}_{3}(\mathrm{u})\right)\left(5.060831165 \mathrm{~T}_{0}(\mathrm{v})+0.03245494687 \mathrm{~T}_{1}(\mathrm{v})-\right.$ $\left.0.0001866545327 T_{2}(v)+0.163082719910^{-5} T_{3}(v)\right)$

By solving the above system will have the solution: $\left(x_{1}=17573.35567, x_{2}=2267.637756, y_{1}=6483.69165\right.$, 
$\left.y_{2}=43.85811217\right)$.

On the computation of values of functions we will have: $y_{1}=6481.594571$ and

$y_{2}=43.84302918$, therefore the changes will be respectively for $y_{1}(-2.097082)$, while for $y_{2}(-0.01508299)$.

Table 2: Table of approximations

\begin{tabular}{|c|c|c|c|c|c|c|c|c|}
\hline \multirow[b]{2}{*}{$\begin{array}{c}\text { Approximation } \\
\text { by }\end{array}$} & \multirow{2}{*}{$\begin{array}{c}\text { Food } \\
\text { voluminous } x_{1}\end{array}$} & \multirow{2}{*}{$\begin{array}{c}\text { the } \\
\text { concentrate } \\
x_{2}\end{array}$} & \multicolumn{2}{|c|}{$\begin{array}{l}\text { from the solution } \\
\text { the weight of the }\end{array}$} & \multicolumn{2}{|c|}{ Estimated value of } & \multicolumn{2}{|c|}{$\begin{array}{l}\text { changes } \\
\text { for }\end{array}$} \\
\hline & & & $\begin{array}{l}\text { milk } \\
y_{1}\end{array}$ & $\begin{array}{c}\text { Beef } \\
y_{2}\end{array}$ & $y_{1}$ & $y_{2}$ & $y_{1}$ & $y_{2}$ \\
\hline Chebishev & 17573.35567 & 2267.637756 & 6483.69165 & 43.85811217 & 6481.594571 & 43.84302918 & -2.097082 & $\begin{array}{l}-0.0150 \\
8299\end{array}$ \\
\hline
\end{tabular}

We note by the approaches that $y_{1} \in[2000,10000]$ and $y_{2} \in[20,60]$. For this reason, the options for the computation of the exact solutions through the MAPLE program are:

$x_{1} \in[10000,20000]$ and $x_{2} \in[1000,5000]$

Exact solutions are $x_{1}=17558.67832, x_{2}=2265.746088, \mathrm{y}_{1}=6478.260594, y_{2}=43.82293176$. It is proved that the maximum of the profit and the minimum of the cost are achieved for $x_{1}=17558.7 \mathrm{~kg}$ voluminous food and $x_{2}=$ $2265.7 \mathrm{~kg}$ concentrate. In this case the amount of milk produced by a cow is $6478.3 \mathrm{~kg}$ while the average weight of calves at birth is $43.8 \mathrm{~kg}$.

The quantity of fresh food $=10535.22 \mathrm{~kg}$,

The amount of dry food $=7023.48 \mathrm{~kg}$,

The amount of concentrate $=2265.7 \mathrm{~kg}$.

The cost is $108185.2 \mathrm{~L}$ and the revenues are $177287.5 \mathrm{~L}$ for a cow in a year. So the profit from one cow is 69102.32 in a year.
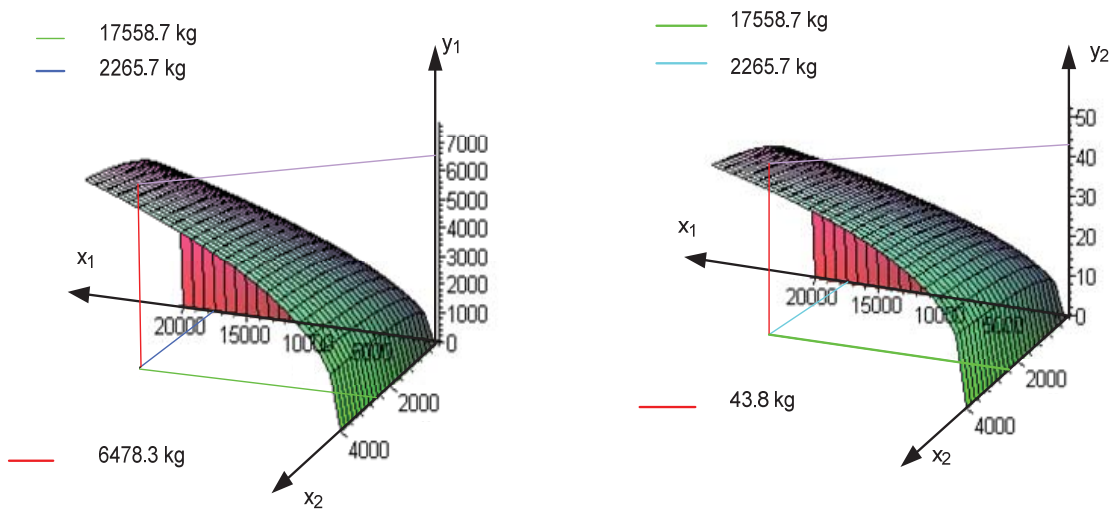

Presentation of milk production function and the average weight of calves at birth $y_{1}=23.31274017 \cdot x_{1}^{0.424} \cdot x_{2}^{0.192}$ dhe $y_{2}=0.3201390009 \cdot x_{1}^{0.331} \cdot x_{2}^{0.218}$ 


\section{Conclusions}

By the study reached the following conclusions:

- During the decision-making process is becoming increasingly evident need for conducting a detailed scientific analysis. Therefore the realization of the livestock production necessarily requires the analysis of the use of the inputs in production.

- Implement the Cobb-Douglas production functions creates the opportunities for the economic analysis of the farm of the

- The study confirmed that the average production levels $(21.25115 \mathrm{~kg}$ of milk per day) the optimal structure would be: $59 \%$ fresh foods, $31 \%$ dry foods and $10 \%$ concentrates.

- In the general case is shown that the maximum of the revenueis achieved for the same amount of inputs that achieve the maximum of the profit.

- Finally, the conditions of our country, would be preferable voluminous system of nutrition.

\section{References}

Allan, R. G. D. (1968) Mathematical Analysis for Economists

A. F. Timan (1994) Theory of Approximation of Functions of a Real Variable

Bruce R. Beattie, C.Robert Taylor.(1998). The economics of Production

Chambers, R. G. (1988) Applied Production Analysis

Chiang, Alpha C. (1984) Fundamental Methods of Mathematical Economics

Christopher F. Baum (2006). An Introduction to Modern Econometrics Using Stata

Cobb, C. W. P. H. Douglas (1928). A Theory of Production. American Economic Revieë 18

David L. Debertin (1986). Agricultural Production Economics

Fare, R. , D. Primont. (1995) . Multi-output Production and Duality

Heady, E. O., J. L. Dillon (1961) Agricultural Production Functions

Knut Sydsaeter, Peter J. Hammond Mathematics for Economic Analysis

Mundlak, Y. (1993) On the Empirical Aspects of Economic Growth Theory., American Economic Review, 83 (2)

Mundlak, Y. (1996) Production Function Estimation: A Revival of the Primal. Econometrica 64 (2)

Peter J. Lambert Advanced Mathematics for Economists

Richard Wateman (1999). Cobb-Douglas Production Function

Sabah Sena (2005). Practical feeding of dairy cattle

Sydsaeter, Knut, Peter Hammond (2002). Essential Mathematics for Economic Analysis 